\title{
H\&M - a role model for organic cotton use in textile processing?
}

\author{
Therese Graß \\ Technical University of Applied Sciences Wildau
}

\begin{abstract}
Sweden's Hennes \& Mauritz (operating as H\&M) is one of the biggest multinational retail-clothing companies in the world. As a result of massive criticism from campaigning nonprofit organizations and news media reports that blamed $H \& M$ for unfair and substandard working conditions in their ancillary industries, in 1997 the company began to develop a corporate social responsibility (CSR) program and a code of conduct. Today H\&M has a wide-ranging, broadly integrated CSR program. As a part of its commitment, the company implemented a strategy to "Use Natural Resources Responsibly". The use of organic cotton, which is understood as cotton grown without chemical pesticides or fertilizers, is one part of the strategy.

In 2010, the company was hit by a scandal. News media reported that large volumes of genetically modified cotton from India had been falsely put on the German market as organic cotton and affected various companies, among them H\&M. The search for better monitoring, controls and safeguards was on so $H \& M$ could keep its promises. This article discusses the challenge and possible improvements and solutions to recognized problems, and evaluates the company's actions so far. It concludes that H\&M can be considered a role model for organic cotton use in textile processing. However, further steps can and should be taken for improved control and information, and better customer and stakeholder relations in the CSR framework.
\end{abstract}

Keywords: corporate social responsibility (CSR), cotton, genetically modified organisms (GMO), labeling, monitoring, organic, textiles

Author: Therese Graß holds B.A. and M.A. degrees in European Management from Technical University of Applied Sciences Wildau.

\section{Introduction}

As the international textile and fashion industry met for the 2010 Berlin Fashion Week, the Financial Times Deutschland reported that large amounts of genetically modified cotton (GM cotton) from India had been falsely put on the German market as organic cotton. Among the major companies affected were firstrank retail chains like $\mathrm{C} \& \mathrm{~A}$, Tchibo, and H\&M. The report put considerable blame on organic certification organizations such as
French Ecocert and the Dutch Control Union: They were accused of certifying GM cotton as organic cotton, giving their seal as approved 100 percent organic when it was certainly not. Both certifiers reacted with strong statements underlining their innocence and irritation about the presented data (Heinze, 2010). News reports also claimed the fraud had already been detected in 2009 but the public had not been informed. Indian agriculture authority Apeda, which had detected the fraud, moved to impose fines on the involved firms (Brambusch, 2010).

Critical attention focused on Swedish multinational H\&M, a popular fashion brand and globally operating retail chain with more than 2600 stores and 94,000 employees (H\&M [1], 2012). $\mathrm{H} \& \mathrm{M}$ not only confirmed cooperation with certifiers Ecocert and Control Union but admitted to have been informed about the false labeling incident since 2009. The company emphasized that the issue was already being discussed with the certifiers, and it admitted that it could not rule out that some of the supplied GM cotton had been used for its textile processing (Wollenschläger, Bartholomew, 2010, p.20).

The Financial Times Deutschland article questioned the general credibility of H\&M's certified organic cotton products. Since the newspaper report's data went unproven, the extent of the fraud was not measurable. Yet H\&M now faced two major problems. The image of the textile giant had suffered serious harm. Customers who had been willing to support organic cotton by paying higher prices felt betrayed, and the issue was if they could trust H\&M's promises. The firm had to rebuild its trust and reputation. Secondly, it became necessary to rethink the relationship with its suppliers or sub-suppliers and with the certification organizations. It had to be ensured that organic cotton offered by $\mathrm{H} \& \mathrm{M}$ is really 100 percent organic.

\section{CSR in the textile industry}

The textile industry is generally characterized by a workintensive production with relatively simple technology and therefore low requirements for worker qualification. It is seen as one of the forerunner of the globalization process by outsourcing whole production stages to countries with very low labor cost.

There are two main reasons for this development. On the one hand, global sales markets have intense price competition. To survive, a textile company has to hold down production cost but 
still be able to react flexibly to quickly-changing fashion trends and their fast realization.

On the other hand, the character of textile production is peculiar. It is not place bound (so fast relocation is always possible), it has low real capital intensity and low demand for high skilled workers. These reasons lead to the consequence that many textile companies manufacture their products with complicated production chains with various contractors, mainly in developing countries. An ancillary effect of this development is the violation of worker rights, the use of child labor and damage to the environment in developing countries (Spönemann, 2009, p. 202).

These issues have been well publicized in developed countries where the main markets are. Public opinion turned against these practices. Activist organizations, campaigns for ethical consumerism, critical media reporting and political pressure have changed stakeholder expectations.

No major brand-conscious textile company operating in developing countries can afford to have no CSR activities addressing these issues. Strict regulatory compliance, voluntary initiatives to improve social and environmental conditions, accountability, communication and transparency have become important (Lynes, Andrachuk, 2008, p. 378).

$\mathrm{H} \& \mathrm{M}$ has been one of the firms most criticized by transnational activist non-profit organizations such as the Clean Clothes Campaign (CCC). Claims that H\&M is guilty of allowing unfair and substandard working conditions in their ancillary industries led to the company's first engagement with CSR in 1997, when H\&M developed its first code of conduct (Spönemann, 2009, p.216).

Since then, H\&M has developed an extensive CSR program that is integrated into different areas; one key commitment is "Use Natural Resources Responsibly." It includes a strategy to procure, process and sell organic cotton as one way to enhance sustainability. But that turned out to be a complex endeavor.

\section{Organic cotton}

According to the Organic Trade Association (OTA), an international business interest group dedicated to organic products,

organic cotton is grown using methods and materials that have a low impact on the environment. Organic production systems replenish and maintain soil fertility, reduce the use of toxic and persistent pesticides and fertilizers, and build biologically diverse agriculture (OTA, 2010).

Organic cotton (in Germany often called "Bio-Baumwolle," or bio-cotton) is not the only category for environmentally improved cotton production. For example, H\&M in 2004 joined the Better Cotton Initiative (BCI), which does not have labels and certifications but still aims to promote improved environmental and social requirements. "Better" cotton is, because it mostly centers on conventional cotton growing, below the standards of organic cotton, which encompasses many more advanced requirements, including government rules such as the European Union's “eco-regulation" (EC 834/2007).

Organic cotton means certified cotton. Third-party independent certification organizations validate that the producers of organic cotton only use methods and materials that are allowed in an organic production cycle.

In most developed countries, it is illegal to claim the result as organic when the production and processing system are not certified. Generally, the certification of organic cotton includes three years of change from conventional practices to organic practices and processes.
In the United States, federal regulations can prohibit the use of GM seed for organic farming. Many countries, e.g. the United States, the European Union and India, have issued government standards for organic cotton production (International Cotton Advisory Committee, 2011).

In $2004 \mathrm{H} \& \mathrm{M}$ began to include small amount of certified organic cotton in certain of their children's garments. Since 2007, there are garments made of 100 percent organic cotton in all departments. Additionally there are garments that are made of 50 percent organic cotton and 50 percent conventional cotton.

All garments that are made from organic cotton have a special hangtag. H\&M has introduced "Conscious Collections" including evening dresses which have been a success. According to the non-profit organization Textile Exchange's Global Market Report on Sustainable Textiles, H\&M was the biggest user of organic cotton in the years 2010 and 2011 (Eriksson, 2011) One part of the company's strategy is the ambitious goal to only use cotton from sustainable sources by 2020 at the latest.

Problems that arise with the production of organic cotton are manifold. It starts with the price of the organic seeds which are more expensive than conventional seeds. Further the seed is very fragile without pesticides and fertilizers, therefore breaks in weather can cause serious harm. A major problem arises with spreading contamination. In recent years, cropping genetically modified cotton has greatly increased. Estimates of the global share of GM cotton range from about half to even 90 percent (Gray, 2012; Renter, 2012).

The consequence is that GM seeds and non-GM seeds are unintentionally being sown together, and it has become extremely difficult to procure purely natural, non-GM cotton. Suppliers' guarantees may well be unreliable, so the need for truthful certification is increasing. The Organic Trade Association notes:

Big chains like C\&A or H\&M that need large quantities of cotton in a short space of time for their eco collections are, as newcomers, forced to rely on documentation alone, since they don't know their suppliers. (Organic Trade Association, 2010)

H\&M tries to protect itself from contaminated organic cotton with a range of methods. All its products containing organic cotton have a transaction certificate issued by the third-party certifiers Institute for Marketecology (IMO, Institut für Marktökologie) and Control Union (H\&M (2), 2012).

After a starting inspection, certified suppliers will be checked once a year, several samples being taken for examination. Further all factories handling organic cotton are certified according to the relevant standards OE (Organic Exchange) 100 and $\mathrm{OE}$ Blended. The 2010 scandal showed, however, that this control system by third-party organizations did not function properly.

Using third-party monitoring and certification has the advantage that a firm like H\&M can show that the company is not hiding anything. The risk lies in the insecurity of the exact work of the certifier.

It came out that Control Union tried to camouflage that massive amounts of organic cotton were contaminated with GM cotton. Even if responsibility for (unintentional or intentional) mistakes in verification can be placed with the certifier organizations, the image and credibility of H\&M suffers from it. It is most likely not a coincidence that in the aftermath of the scandal, H\&M changed its certification contrast from Ecocert to the IMO.

Furthermore, certification standards were questioned: under the OE 100 standard, purchasing, handling and use of 100 percent organic cotton were tracked but any use of postharvest chemical treatment, such as the coloring process, was not under watch (TE, 2012). This information is not found on the H\&M website and may lead to confusion among customers. 


\section{Potential improvements}

What can be done to improve control and verification? I propose to build on two approaches. On the one side, H\&M could establish its own control unit for organic cotton production and related textile processing. On the other side, it is advisable to enlighten customers' purchasing decisions by an improvement of product labeling.

In addition to the independent third-party certifier organizations. H\&M should consider building its own control union. Operating as a company which has no production units of its own, H\&M is dependent on correct operating principles of suppliers and sub-suppliers. Given today's market realities and agricultural practices, H\&M is always facing the danger of abuse and fraud. Especially the production of organic cotton which has a recovery phase of three years from conventional to organic cotton needs a strict supervision. A few GM seeds can contaminate whole fields of valuable organic cotton. Risk is so high that a serious commitment to organic production justifies, even demands, that $\mathrm{H} \& \mathrm{M}$ puts expert verification under its own control.

H\&M then could decide how many and what people are involved, how often and which criteria will be examined. This will not replace the third-party certifiers; indeed H\&M's extra care will support their work. Further, the concept is not just about examination and criteria for organic production. It would make sense to commit time and resources to explain the benefits, value and sustainability of organic cotton to local farmers.

Such efforts could avoid exposure of H\&M to new scandals about its organic cotton, which could lead to accusations that $\mathrm{H} \& \mathrm{M}$ is engaging in "greenwash," which may lead to massive image damage. "Greenwashing is the act of misleading consumers regarding the environmental practices of a company or the environmental benefits of a product or service" (Delmas, Cuerel Burbano, 2011, p. 66).

H\&M already has experience with auditing its suppliers. According to recent H\&M sustainability reports, many suppliers and sub-suppliers have been inspected on a regular basis in order to prevent child labor and human rights violations. H\&M has the advantage of many years of experience of building up, implementing and running of a control unit. Given H\&M's ambitious aim to use only cotton from sustainable sources by 2020, relying only on third-party certification will not be enough.

The disadvantage of the proposal is the high expenditure that will arise with a new control unit. Especially the starting phase where the whole unit will be formed and structured will cause substantial costs. The hiring and relocating of several employees is a further matter of expense. Another disadvantage is the direct accusation in cases of e.g. new contaminations with GM seeds. In the above mentioned scandal, H\&M could reject direct responsibility and shift blame to third-party certifiers. By having its own control unit, H\&M would in the future accept direct responsibility for failure to control and supervise production, thus the company's integrity could and would be questioned.

The second proposal leads to more precise labeling of the garments that are produced with organic cotton. At the moment garments have a green label when completely or partly produced with organic cotton. That labeling is not very precise and does not give any information about origin and processing of organic cotton used. Customers are often confused by these labels. In many cases organic cotton or partly organic cotton is used to produce the garments but the coloring is still done with chemical substances, so "organic" is only correct for the original fiber.

The advantage would be that the customers and also sales personnel get more information and feel that the company makes an effort to clarify the process and involve them. The disadvantage is again the costs of more differentiated labeling. While the production of new labels is not an expensive factor, the precise classification of the garments is.

A further suggestion may be more information given on organic cotton on the corporate websites and in H\&M's sustainability report. The 2011 H\&M sustainability report provides very limited information about the whole organic cotton production process. Customers who are really interested to learn more about the topic only get a handful of facts on the company's achievements. H\&M could explain more, including the complex challenges of securing its goals for the long supply chain.

\section{Stakeholder perspectives}

$\mathrm{H} \& \mathrm{M}$ is a customer-focused company. It is very important for the firm to meet and understand customers' needs (H\&M, 2011). Implementing a new control unit does not affect customers directly, but in the end they would benefit by knowing that their purchased garments are from repeatedly controlled organic cotton and they can rely and trust H\&M. The second proposal to optimize labeling would be supporting customer information and involvement. If the customer is willing, he can inform himself by studying better information on the hangtag and other company sources.

Suppliers are also important stakeholders. They are valued business partners. H\&M claims that it relies on stable and long term relationships as a key factor for mutual growth. Concerning the first proposal, some suppliers may react negatively to more direct control, and understand they are being criticized. Extra controls could be interpreted as absence of trust and that H\&M is assuming that supplier are inable to handle the cotton production according to accepted and agreed standards.

Toward these stakeholders, it is also necessary to take time to explain and clarify the need for pure organic cotton and controls on a regular basis. Furthermore, extra controls may involve critical reviews, new methods and adapting to new standards, all of which lead to more work and expenses for the suppliers. But $H \& M$ could make an effort to lead suppliers to see the control unit as helpful and supportive, and to understand there is potential benefit from the proposed system.

Reimann (2012) argues that local employees in emerging economies often value social engagement by their employer. That may also be adaptable to environmental commitments. If suppliers understand the benefit of organic cotton, the need of regulated control and the value of long term relationships, they may support it. And indeed there may be a social benefit: organic cotton production without pesticides and chemical fertilizers also supports local workers' health.

\section{Challenges ahead}

If $\mathrm{H} \& \mathrm{M}$ delivers on the promise to produce all garments with sustainable cotton by 2020 , it seems likely that implementation of an internal control program is needed sooner or later. H\&M already has a Full Audit Program (FAP) for compliance with human rights, child labor and industrial safety standards. If organizing such an effort was deemed necessary for social responsibility, then it is hard to imagine that management can decide otherwise on the natural sustainability issues of organic cotton.

There is a realistic prospect to integrate an own control unit beside the third-party certifier organizations - into the already existing FAP. The proposal could win management and stakeholder support by underlining the need of credibility concerning 
organic cotton and the reputation of H\&M. It could be seen as a protective shield in the framework of issue and risk management.

One influential factor is how customers' attitudes toward sustainability and the use of GM cotton develop. Imagining that the awareness of the customers will grow in the next years, H\&M could be a role model for the industry by having fuller control and a reliably certified organic cotton production.

A similar situation will arise with the implementation of a precise labeling system for garments produced full or partly from organic cotton. A sustainable-thinking customer will favor a hangtag that gives complete information about the amount of organic cotton that is used for the garment, the origin of the organic cotton, and how the coloring and treatment was done. Further, third-party certifiers could be mentioned on the hangtag as well, giving interested customers an opportunity to look them up, potentially enhancing their standing.

It is conceivable that this proposal will not win as much support as needed. H\&M has never fully disclosed its supply chain. The company offers certain information which it believes necessary to publish. While researching information for this case study, I found that the $2011 \mathrm{H} \& \mathrm{M}$ sustainability report included much less information on suppliers than older sustainability reports of the same company: the older editions all had a large appendix including results and strategy of their FAP. The 2011 report did not include the FAP results. Whatever the reasons for cutting this information, future H\&M resistance to publishing this internal information could be an obstacle for the precise labeling of organic cotton garments.

\section{Conclusion}

To answer the question of this case study whether H\&M can be considered a role model of using organic cotton in textile processing, the answer should definitely be yes. By being the biggest user of organic cotton in past years, H\&M is really trying to integrate organic cotton into its textile processing. Being hit by a scandal in 2010 did not discourage the company to stick to their organic cotton usage and their aim to use only sustainable organic cotton by 2020. H\&M should be credited for its endurance, which is the key factor which will help the firm to reach its ambitious goal.

It would be advisable to establish a control unit soon as possible. Responsibility for a successful introduction should be assumed by the CSR department in strong connection with the finance and human resources departments. Development could be done by the CSR department at headquarters in Sweden.

Some caveats are in order. While ethical consumerism and ethical sourcing have been on the rise together with public and business community awareness of ecology and sustainability, it is still true that a lot of customers do not personally care much whether their basic white T-shirt, which is worn barely a few times a year, is from organic or from conventional cotton. Customer readiness to reward $\mathrm{H} \& \mathrm{M}$ for an all-out pro-organic effort may be quite limited, and management is probably aware of that.

The Swedish fashion giant follows a philosophy to produce good quality for a small price, and also aspires to be fashionable and up-to-date. These are the basic ingredients of H\&M's commercial success. The pressure to compromise on some points will always be great. These may be continued use of conventional cotton, low-cost labor in poor countries under precarious and unsafe conditions, and environmental damage. H\&M will face a broad range of CSR challenges in the future; and the organic cotton challenge is just one of many.

\section{References}

Brambusch, J. (2010). Das Geschäft mit falscher Biowolle. Financial Times Deutschland. Retrieved 28 January 2013 from http://www.ftd.de/unternehmen/industrie/:agenda-das-geschaeft-mitfalscher-biowolle/50063966.html?mode=print

Eriksson, A. (2011). H\&M ranked as the number one user of organic cotton worldwide 2010. Finanznachrichten.de. Retrieved 30 January 2013 from http://www.finanznachrichten.de/nachrichten-201109/21263985-h-m-hennes-mauritz-ab-h-m-ranked-as-the-number-oneuser-of-organic-cotton-worldwide-2010-004.htm

Delmas, M. A. \& Cuerel Burbano, V. (2011). The drivers of greenwashing. California Management Review 54(1), 64-87.

Gray, L. (2012, 8 October). Most cotton we wear is GM today. The Telegraph. Retrieved 2 November 2013 from http://www.telegraph.co.uk/earth/earthnews/9590556/Most-cotton-wewear-is-GM-today.html

Heinze, K. (2010). Cotton scandal: gene technology is the problem. Organic-market.info. Retrieved 28 January 2013 from http://www.organicmarket.info/web/Know_How/Cotton/219/0/60/7073.html. 21.10.2012

H\&M (2011). Conscious actions. Sustainability report 2011. Retrieved 30 January 2013 from

$\mathrm{http}: / /$ about.hm.com/content/dam/hm/about/documents/masterlanguag e/CSR/reports/Conscious percent20Actions percent20Sustainability percent20Report percent202011.pdf

H\&M (1) (2012). About H\&M. Fashion and quality at the best price. Retrieved 29 January 2013 from http://about.hm.com/content/hm/AboutSection/en_gb/About.html

H\&M (2) (2012). Towards more sustainable cotton. Retrieved 30 January 2013 from

http://about.hm.com/content/hm/AboutSection/en/About/Sustainability /Commitments/Use-Resources-Responsibly/RawMaterials/Cotton.html

International Cotton Advisory Committee (2011), Descriptions of production programs: Organic, Fair Trade, Cotton Made in Africa, and The Better Cotton Initiative. Retrieved 28 January 2013 from http://icac.org/wp-content/uploads/2011/05/509-Att-3-Description-ofProduction-Programs.pdf

Organic Trade Association (2010). Organic cotton facts. Retrieved 28 January 2013 from

http://www.ota.com/organic/mt/organic cotton.html

Reimann, F., Ehrgott, M., Kaufmann, L., Carter, C. R. (2012). Local stakeholders and local legitimacy: MNEs social strategies in emerging countries. Journal for International Management 18, 1-17.

Renter, E. (2012, 1 November). "Nice shirt—is that GM cotton?" - How genetically modified cotton is taking over. Natural Society. Retrieved 2 November 2013 from http://naturalsociety.com/gm-cotton-90percent-worldwide-crop/

Spönemann, R. (2009). Der Code of Conduct von H\&M, in E. Ehmke, M. Fichter, N. Simon, B. Zeuner (eds.), Internationale Arbeitsstandards in einer globalisierten Welt (pp. 202-223). Wiesbaden: VS.

TE Textile Exchange (2012). OE Standards. Retrieved 30 January 2013 from http://textileexchange.org/content/oe-standards

Wollenschläger, U. \& Bartholomew, F. (2010, January). EtikettenSchwindel bei Biobaumwolle; C\&A, H\&M und Tchibo in Betrug verwickelt, keine internationalen Standards. TextilWirtschaft, 20.

\section{Links}

$\rightarrow$ Better Cotton Initiative (BCI): http://bettercotton.org/

$\rightarrow$ Control Union Certifications: http://certifications.controlunion.com

$\rightarrow$ Ecocert: http://www.ecocert.com

$\rightarrow$ Institute for Marketecology (IMO): http://www.imo.ch

$\rightarrow$ Organic Trade Association (OTA): http://www.ota.com

$\rightarrow$ Textile Exchange: http://textileexchange.org/ 